San Jose State University

SJSU ScholarWorks

Master's Theses

Master's Theses and Graduate Research

Summer 2019

\title{
A Comparison of the Relationship Between Gender Adherence, Sex, and Attitudes Toward Individuals With a Mental Illness
}

Brooke Reimer

San Jose State University

Follow this and additional works at: https://scholarworks.sjsu.edu/etd_theses

\section{Recommended Citation}

Reimer, Brooke, "A Comparison of the Relationship Between Gender Adherence, Sex, and Attitudes Toward Individuals With a Mental Illness" (2019). Master's Theses. 5042.

DOI: https://doi.org/10.31979/etd.kb9v-xgrd

https://scholarworks.sjsu.edu/etd_theses/5042

This Thesis is brought to you for free and open access by the Master's Theses and Graduate Research at SJSU ScholarWorks. It has been accepted for inclusion in Master's Theses by an authorized administrator of SJSU ScholarWorks. For more information, please contact scholarworks@sjsu.edu. 
A COMPARISON OF THE RELATIONSHIP BETWEEN GENDER ADHERENCE, SEX, AND ATTITUDES TOWARD INDIVIDUALS WITH A MENTAL ILLNESS

\author{
A Thesis \\ Presented to \\ The Faculty of the Department of Psychology \\ San José State University \\ In Partial Fulfillment \\ of the Requirements for the Degree \\ Master of Science
}

by

Brooke Reimer

August 2019 
(C) 2019

Brooke Reimer

ALL RIGHTS RESERVED 
The Designated Thesis Committee Approves the Thesis Titled

A COMPARISON OF THE RELATIONSHIP BETWEEN GENDER ADHERENCE, SEX, AND ATTITUDES TOWARD INDIVIDUALS WITH A MENTAL ILLNESS

by

Brooke Reimer

APPROVED FOR THE DEPARTMENT OF PSYCHOLOGY

SAN JOSÉ STATE UNIVERSITY

August 2019

Howard Tokunaga, Ph.D.

Department of Psychology

Megumi Hosoda, Ph.D.

Department of Psychology

Lisa Weisman-Davlantes,

Department of Psychology, California

Psy.D., LMFT

State University, Fullerton 


\begin{abstract}
A COMPARISON OF THE RELATIONSHIP BETWEEN GENDER ADHERENCE, SEX, AND ATTITUDES TOWARD INDIVIDUALS WITH A MENTAL ILLNESS
\end{abstract}

by Brooke Reimer

Attitudes toward persons with a mental illness consist of four main dimensions: Authoritarianism, benevolence, social restrictiveness, and community mental health ideology. Attitude differences on these dimensions have been found among many types of groups, including age, race, and educational attainment. Sex and gender adherence have been cited as other such factors, but two major issues are present: past researchers have reported inconsistent findings regarding attitude differences and the terms are used interchangeably in research literature despite conceptual differences. Using data from 187 individuals from a survey, the current study tested sex differences and gender adherence differences in attitude toward mental illness independent of each other; incremental effects of gender adherence beyond sex and sex beyond gender adherence were also tested. Results showed no sex differences on all dimension of attitudes, suggesting that sex is not related to attitudes toward persons with a mental illness. Gender adherence differences were found to a limited extent: participants who adhered to feminine gender reported more benevolence than did participants who adhered to no gender. No other gender adherence differences were found. No incremental effects of sex were present above and beyond the effects of gender adherence; however, there was a significant incremental effect of gender adherence above and beyond the effect of sex, but only for the benevolence dimension, suggesting that gender adherence is a better predictor of benevolent attitudes than is sex. 


\section{ACKNOWLEDGEMENTS}

To my committee: I am beyond grateful to have such an amazing team help me finish this project. Thank you so much, Howard, for your support, guidance, \& patience through this journey. Thank you, Megumi \& Lisa - your feedback \& proofreading were invaluable to me, \& I'm so glad I could have you two on my committee.

Kyle, your confidence in me, patience, \& support gave me the strength \& perseverance to complete one of my most challenging goals. You helped me believe in myself, \& my confidence has grown exponentially since starting this project because of that. Thank you for always and forever being there for \& with me in the highs \& lows.

Carlos, Roxy, \& Shawn, thank you for the memes, friendship, \& insanity that you guys have subjected me to all these years. Christine, thank you for the social support during some rough times \& for the boba study break outings - they both made a huge difference. Vanessa \& Ryan, thank you for your mentorship, acceptance, \& community in undergrad \& beyond. Jonathan, thank you for your companionship \& patience - they've helped more than you know. Diana, thank you for your friendship, support, \& openness during our time in grad school. Dylan, thank you for the reminders that we could do this! David \& Irina, thank you for the support \& flexibility at work so I could get this project done. Thank you, Dr. Sy, for your mentorship \& guidance in undergrad - they laid the foundation for a career that I'm passionate about. Thank you, Cindy, Akanksha, \& Justine for helping create places of solace.

And to my family: thank you for giving me the motivation to go to grad school \& get my degree. I am so grateful for the extra pushes that have brought me here. 


\section{TABLE OF CONTENTS}

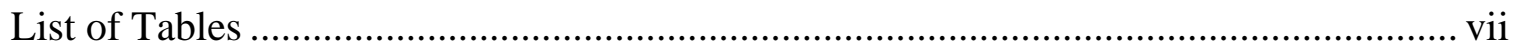

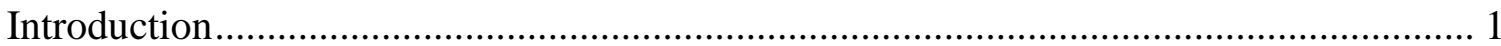

Attitudes Toward Persons With Mental Illness ............................................................

Background Predictors of Attitudes Toward Persons With Mental Illness .....................5

Demographic Predictors of Attitudes Toward Persons With Mental Illness ..................7

Sex as a Predictor of Attitudes Toward Persons With Mental Illness ............................

Gender as a Predictor of Attitudes Toward Persons With Mental Illness ....................11

Sex and Gender as Predictors of Attitudes Toward Persons With Mental Illness .......14

The Current Study .................................................................................................

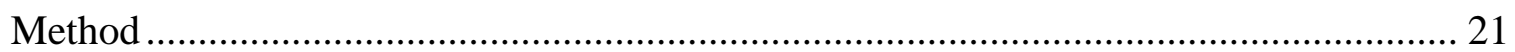

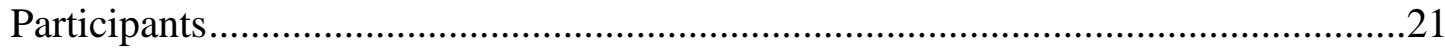

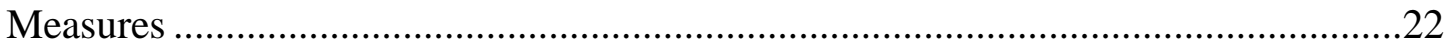

Attitudes Toward Persons With Mental Illness. ................................................ 22

Gender Role Adherence ................................................................................. 25

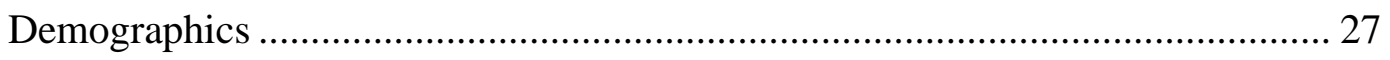

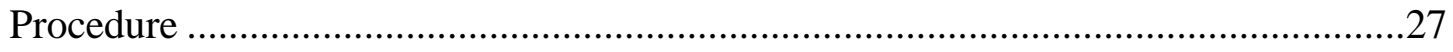

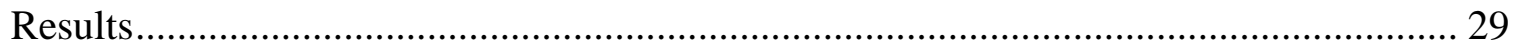

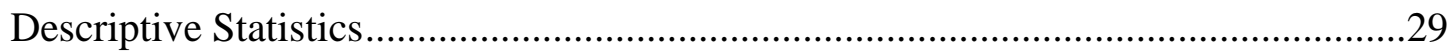

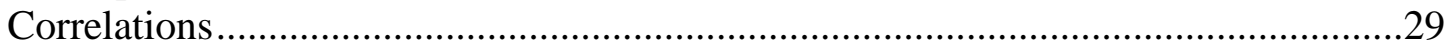

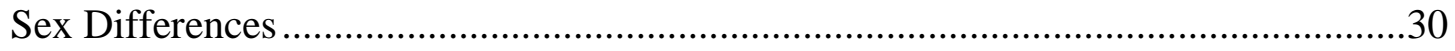

Gender Role Adherence Differences .....................................................................

Hierarchical Multiple Regression ..........................................................................

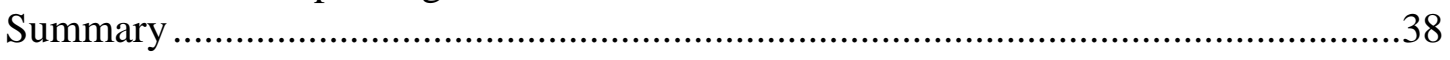

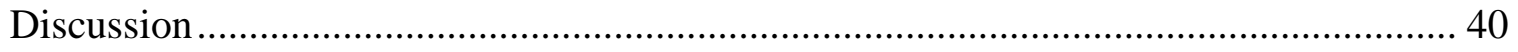

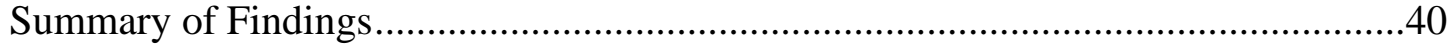

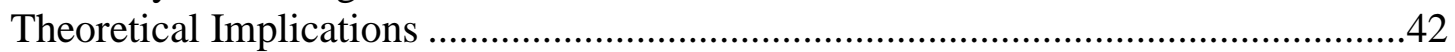

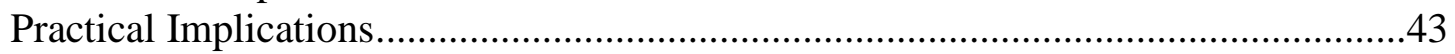

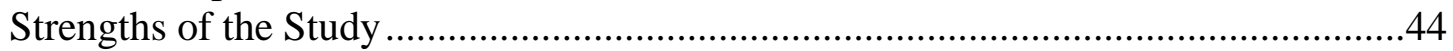

Limitations and Directions for Future Research ………………………………........45

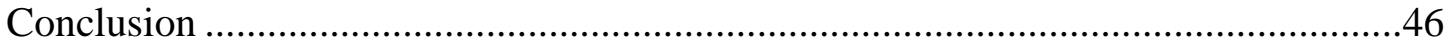

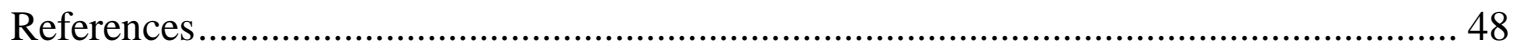




\section{LIST OF TABLES}

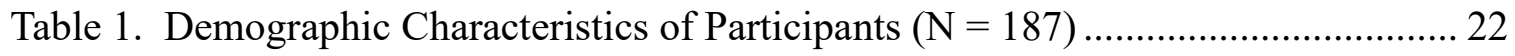

Table 2. Descriptive Statistics and Bivariate Correlations, CAMI Subscales $(\mathrm{n}=185)$

Table 3. Community Attitudes Toward the Mentally Ill by Sex 30

Table 4. Means, Standard Deviations, and One-Way Analysis of Variance (ANOVAs) for Effect on Gender Adherence on Attitudes Toward Individuals With Mental Illness

Table 5. Hierarchical Multiple Regression Testing The Incremental Effect of Sex Over and Above the Effect of Gender Adherence on Authoritarianism $(\mathrm{N}=185)$

Table 6. Hierarchical Multiple Regression Testing The Incremental Effect of Sex Over and Above the Effect of Gender Adherence on Benevolence $(\mathrm{N}=185)$

Table 7. Hierarchical Multiple Regression Testing the Incremental Effect of Sex Over and Above the Effect of Gender Adherence on Social Restrictiveness $(\mathrm{N}=185)$

Table 8. Hierarchical Multiple Regression Testing the Incremental Effect of Sex Over and Above the Effect of Gender Adherence on Community Mental Health Ideology $(\mathrm{N}=185)$.

Table 9. Hierarchical Multiple Regression Testing the Incremental Effect of Gender Adherence Over and Above the Effect of Sex on Authoritarianism $(\mathrm{N}=185)$

Table 10. Hierarchical Multiple Regression Testing the Incremental Effect of Gender Adherence Over and Above the Effect of Sex on Benevolence $(\mathrm{N}=185)$.

Table 11. Hierarchical Multiple Regression Testing the Incremental Effect of $g$ Gender Adherence Over and Above the Effect of Sex on Social Restrictiveness $(\mathrm{N}=185)$.

Table 12. Hierarchical Multiple Regression Testing the Incremental Effect of Gender Adherence Over and Above the Effect of Sex on on Community Mental Health Ideology $(\mathrm{N}=185)$ 38 


\section{Introduction}

Individuals with disabilities face barriers to the benefits of work due to discrimination from co-workers, supervisors, and subordinates (Kukla, Bond, \& Xie, 2012). In particular, mental illness poses a challenge due to the invisible nature of the disability (Goodman-Delahunty, 2000; Hebl \& Skorinko, 2005; Jans, Kaye, \& Jones, 2011; Phelan \& Basow, 2007; Roberts \& Macan, 2006; Russinova, Griffin, Bloch, Wewiorski, \& Rosoklija, 2011; von Schrader, Malzer, \& Bruyère, 2014). Addressing discrimination requires understanding the underlying mechanisms that lead to discriminatory behavior. Understanding attitudes toward individuals with a mental illness is one such way of reducing discrimination against disabled individuals. Predicting these attitudes using background factors such as sex and gender helps researchers and practitioners create better intervention programs by providing a better understanding of the underlying mechanisms of discrimination. However, few researchers in the past have separated sex from gender, instead using the terms "sex" and "gender" interchangeably and ignoring significant conceptual differences between them. The goal of the present study was to explore differences between sexes and genders in their attitudes toward persons with a mental illness and to explore the independent predictive powers of sex and gender on these attitudes.

\section{Attitudes Toward Persons With Mental Illness}

The Americans with Disabilities Act of 1990 (ADA) set out to define disabilities and establish the importance of the inclusivity of disabled individuals in the United States ("Introduction to the ADA," n.d.). The ADA defines disability as "a physical or mental 
impairment that substantially limits one or more major life activity" of an individual ("Introduction to the ADA," n.p.). Mental disorders (interchangeable with mental illness) are invisible disabilities (i.e., disabilities that do not have a characteristic that is easily identified by others) that merit attention due to higher rates of discrimination relative to visible disabilities (i.e., disabilities that have a characteristic that is easily identified by others) (Gewurtz, Langan, \& Shand, 2016). Mental illnesses are "conditions that affect [an individual's] thinking, feeling, mood, and behavior...may be occasional or longlasting (chronic)... [and] can affect [an individual's] ability to relate to others and function each day" ("Mental Disorders," 2014, n.p.). For the purposes of this study, a mental illness is any psychiatric or psychological disorder. Examples of mental illness are major depressive disorders, anxiety disorders, post traumatic-stress disorders, schizophrenia, obsessive-compulsive disorders, and personality disorders (Gordon, 2003). The ADA prohibits discrimination of individuals with disabilities, including persons with mental illness, and requires that employers provide reasonable accommodations for these individuals ("Introduction to the ADA," n.d.).

Attitudes toward mental illness are considered key elements in discrimination against persons with mental illness (Alexander \& Link, 2003; Smith \& Cashwell, 2011). Attitudes toward persons with mental illness are defined as cognitions and beliefs about persons who are known to have a mental illness. Due to the effects of attitudes on the treatment of persons with mental illness, early research on attitudes toward persons with mental illness assessed clinicians' perspectives. However, as mental health issues have become more public, recent efforts have been made to assess attitudes of laypersons in 
order to better understand how individuals who do not work as mental health professionals view persons with mental illness (Taylor \& Dear, 1981). From this movement, the Community Attitudes toward Mental Illness (CAMI) scale was developed by adapting a previous measure of clinicians' attitudes toward persons with mental illness (Taylor \& Dear, 1981).

There are four dimensions that comprise the original CAMI scale: authoritarianism, benevolence, social restrictiveness, and community mental health ideology (CMHI) (Taylor \& Dear, 1981). These dimensions encompass researchers' aims of providing a means of understanding and assessing the integral cognitions and beliefs of laypeople's attitudes toward persons with mental illness, mental illnesses, and mental health services within their social and geographical communities.

The first CAMI dimension, authoritarianism, is the belief of the inferiority of persons with mental illness and the belief that persons with mental illness are fundamentally different from the general population. Individuals who are highly authoritarian view persons with mental illness as inferior and in need of strict discipline as well as intense treatment plans such as hospitalization. Highly authoritarian people might treat a person with mental illness like a child, patronizing the decisions and behaviors of the person as though he or she cannot function as an independent individual.

Benevolence is the holding of sympathetic cognitions regarding mental illness and persons with mental illness. Those who are highly benevolent believe individuals with mental illness are in need of special treatment, should be treated with sympathy, and are not a burden to society. Benevolent individuals might unintentionally treat individuals 
with mental illness in a condescending manner that stems from the attitude that the mentally ill should be given special consideration and treatment.

Social restrictiveness is the belief that persons with mental illness are a societal threat and that one should maintain social distance from or reduce social closeness with them. Individuals who are socially restrictive view individuals with mental illness as dangerous to themselves and others, unable to handle social interactions (friendships, relationships, family, etc.), and needing to be kept at a physical distance from others in society (e.g., being kept in a mental hospital). Socially restrictive individuals might refuse to create or maintain close personal relationships with persons with mental illness, or terminate a relationship upon discovering the disability.

Community mental health ideology reflects beliefs regarding the benefits of integrating persons with mental illness into one's geographical and social community. Those with positive community mental health ideology are accepting of persons with mental illness in their community and tend to more readily accept the presence of local community mental health resources. These individuals might advocate for the rights of persons with mental illness and support legislation for the development of local mental health resources. Those with negative community mental health ideology believe that institutionalization of persons with mental illness is beneficial to one's community (Taylor \& Dear, 1981). These individuals might discourage the creation of local mental health resources, instead arguing in favor of institutionalization of the mentally ill. 


\section{Background Predictors of Attitudes Toward Persons With Mental Illness}

Researchers have previously identified several background factors that predict attitudes toward persons with mental illness. Among these background factors are religious beliefs and values, familiarity with mental illness, socioeconomic status, and career profession (Smith \& Cashwell, 2011; Taylor \& Dear, 1981).

Religious beliefs and values include religious denominational affiliation and church attendance. In one study of a number of denominational affiliations, individuals who identified as Pentecostal or Greek Orthodox demonstrated the most authoritarian attitudes; those who identified as Baptist or Salvation Army held the least authoritarian attitudes (Taylor \& Dear, 1981). The highest levels of benevolence were reported by individuals from Baptist and United Church denominations; those who identified as Pentecostal or Greek Orthodox reported the least benevolence among the surveyed denominations. Social restrictiveness was highest and community mental health ideology was most negative among those who regularly attended a church relative to those who did not attend church regularly.

Familiarity with mental illness refers to whether an individual or someone close to the individual (such as a friend or family member) has used mental health services in the past (Taylor \& Dear, 1981). Those who were more familiar with mental illness have been found to be less authoritarian, more benevolent, less socially restrictive, and hold more positive community mental health ideology relative to those who were not familiar with mental illnesses (Strohmer, Grand, \& Purcell, 1984). Pennington, Campbell, Monk, and Heim (2016) found that even when individuals simply imagined social contact with a 
person with mental illness, their overall attitudes improved 24 hours after the initial imagined contact. When participants were prompted to reflect on and adjust their biases and attitudes after the imagined contact, the improvement was even greater than those who were not prompted.

Socioeconomic status includes factors such as educational level, ownership or rental of residence, household income, and occupation status (Taylor \& Dear, 1981). It has been found that higher educational levels are related to lower authoritarian, greater benevolence, lower social restrictiveness, and more positive community mental health ideology (Strohmer et al., 1984; Taylor \& Dear, 1981; Yuan et al., 2016). Individuals who owned a home have been found to have less sympathetic attitudes toward persons with mental illness than individuals who rented their occupied residence (Taylor \& Dear, 1981). Although Taylor and Dear (1981) found that household income did not have a significant relationship with benevolence and community mental health ideology, Williams, Cabrera-Nguyen, and Johnson (2018) reported that those with high incomes tended to be more socially restrictive. Further, those who held a high-status occupation demonstrated more sympathetic attitudes toward those with a mental illness relative to those who had a lower occupational status (Taylor \& Dear, 1981; Yuan et al., 2016).

It has also been demonstrated that a person's type of occupation is significantly related to his or her attitudes toward persons with mental illness. Smith and Cashwell (2011) found that if individuals' career involved work with persons with mental illness, their attitudes were less authoritarian relative to those whose professions did not involve direct interactions with persons with mental illness. However, attitudes may differ based 
on the type of job within the mental health profession. Relative to the rest of the surveyed healthcare professionals, such as administrators or nurses working outside of the mental health field, nurses and health professionals working within a mental ward reported more authoritarianism, less benevolence, and more desired social distance (Cremonini, Pagnucci, Giacometti, \& Rubbi, 2018). Nursing students have been found to have somewhat negative attitudes toward persons with mental illness, especially regarding the benevolence dimension (Millar, 2017).

\section{Demographic Predictors of Attitudes Toward Persons With Mental Illness}

Previous researchers have established several demographic factors that significantly predict attitudes toward persons with mental illness; among these include age, culture, ethnicity, race, marital status, and age of one's children. In general, older individuals tend to be more authoritarian, less benevolent, and more socially restrictive when compared to younger adults (Ewalds-Kvist, Högberg, \& Lützén, 2013; Hunter, Rice, MacDonald, \& Madrid, 2014; Taylor \& Dear, 1981).

In one study of culture, Japanese international students and American students in an American college were assessed on their attitudes toward persons with mental illness (Masuda et al., 2009). The authors found that these Japanese international students reported being more authoritarian, less benevolent, more socially restrictive, and held less positive community mental health ideology than did American students. Other authors measured attitudes of individuals within their country of origin. In one such study, Ethiopian housewives were found to be the least authoritarianism, most benevolent, and least socially restrictive relative to other demographics such as Ethiopian university 
students and employed individuals in Ethiopia (Reta, Tesfaye, Girma, Dehning, \& Adorjan, 2016). In a study measuring attitudes of participants living in India, those with a higher social class showed less authoritarianism than those with lower classes, and those who were married or only had a primary education were the least benevolent and had the most negative community mental health ideology compared to their unmarried or less educated counterparts, respectively (Venkatesh, Andrews, Mayya, Singh, \& Parsekar, 2015).

It has been found that marital status and the age of an individual's children are significant predictors of attitudes toward persons with mental illness. In terms of marital status, it was found that those who were married demonstrated the most authoritarianism, least benevolence, most social restrictiveness and most negative community mental health ideology (Yuan et al., 2016), whereas couples who were separated demonstrated the most positive community mental health ideology (Ewalds-Kvist et al., 2013). Further, the age of an individuals' children has also been shown to predict attitudes toward persons with mental illness. Those with children under the age of 18 have been found to be more authoritarian, less benevolent, more socially restrictive, and less positive regarding community mental health ideology relative to parents of adult children (Taylor \& Dear, 1981).

In addition to the predictors discussed above, sex and gender are two established predictors of attitudes toward mental illness. The following two sections will discuss the constructs and outline previous findings of studies using these variables to predict attitudes toward those with a mental illness. 


\section{Sex as a Predictor of Attitudes Toward Persons With Mental Illness}

Sex is typically defined as a binary category (male and female) into which individuals are assigned at birth and is typically based on the physiological makeup of an individual's reproductive organs and secondary sex characteristics. Sex categories are usually

determined by a socially agreed upon set of criteria; in western culture, sex is binary and determined by the type of reproductive organs present at birth (West \& Zimmerman, 1987). However, there is currently an increased visibility of intersex people (e.g., individuals who do not fit into the binary) and transsexual people (individuals who desire to or who have already undergone sex reassignment, transitioning from the sex they had at birth to the opposite sex through hormone therapy and surgery). Unfortunately, in many research studies, intersex and transsexual people are overlooked or lumped together with individuals who have been assigned a binary sex, leading to their underrepresentation in empirical research literature. As such, future research needs to take into consideration the groups of individuals who do not fit this have undergone or wish to undergo this transition.

For the current study, sex is defined as whether an individual has primary and secondary sex characteristics that pertain to male, female, or some combination of these characteristics, regardless of the reason (e.g., for gender-affirming reasons, to more closely match binary categories of sex), degree (e.g., currently in the process or have completed desired changes), or timing of these changes (e.g., assigned at birth, began changes in adolescence or adulthood). The categories include male, female, transsexual 
male-to-female, and transsexual female-to-male, and intersex. Participants will be given the option to self-report any sex category with which they most closely identify.

The relationship between sex and attitudes toward persons with mental illness is a complicated one. In general, females, relative to males, have been found to hold attitudes that reflect less authoritarianism, more benevolence, and more positivity regarding community mental health resources (Chen \& Chandrasekara, 2016; Ewalds-Kvist et al., 2013; Upadhyay, Srivastava, Singh, \& Poddar, 2016); however, females also tend to be more socially restrictive (Taylor \& Dear, 1981). Further, researchers have uncovered inconsistent results regarding how the sex of an individual predicts attitudes toward people with mental illness. For example, Hinkelman and Granello (2003) reported that there was a significant relationship between sex and attitudes, with males relative to females demonstrating significantly less benevolence and more social restrictiveness. However, Wendt and Shafer's (2016) study demonstrated minimal sex differences on attitudes toward mental illness. Kivari's (2009) study showed that sex was related to negative (anxiety, relationship disruption, hygiene, and visibility) attitudes toward mental illness but not to positive attitudes (treatability, professional efficacy, and recovery), such that males held more negative attitudes than did females but sex was not significantly related to the positive attitudes scale used in the study. Moreover, Hampton and Sharp (2014) reported that males and females did not differ in their shame-related attitudes of mental illness (e.g., attitudes that reflect perceptions of internal shame and community and family stigmas). 
Kivari (2009) suggests that a possible explanation for inconsistent results regarding sex differences is methodological, reporting that the effect sizes of the samples in some studies may factor into sex's ability to explain differences in attitudes; smaller effect sizes may explain why sex is an inconsistent predictor of attitudes toward mental illness. Kivari (2009) illustrates this by explaining that a national study on sex differences found a significant difference for sex due to the large sample but other studies with smaller sample sizes did not report significant sex differences (Corrigan \& Watson, 2017, as cited in Kivari, 2009, p. 6).

Some researchers suggest that the effect of sex may depend on other factors (Hinkelman \& Granello, 2003; Kivari, 2009; Venkatesh et al., 2015). In one example, Smith and Cashwell (2011) looked at the relationship between participants' sex and occupation type (mental health professions and non-mental health professions). They found that the attitudes differences between the sexes further differed depending on the type of occupation. In general, there was a main effect of sex such that females relative to males desired less social distance from persons with mental illness, regardless of whether or not they were mental health professionals. However, when considering job profession type, males who were mental health professionals desired higher levels of social distance than any other combination of these two categories.

\section{Gender as a Predictor of Attitudes Toward Persons With Mental Illness}

Related to sex is the social construct of gender. Although once considered a direct result of sex, gender is now defined as a socially-derived, non-physical set of characteristics that make up part of an individual's identity and behaviors, typically 
rooted in an individual's cultural norms (Marini, 1990; Pentony, 1980; West \& Zimmerman, 1987). Traditionally, in western culture, gender role categories are binary (men and women) and involve corresponding binary characteristics (masculine and feminine) and behaviors (e.g., men work for an income and women take care of children). Due to gender once being considered directly derived from one's physiology, males were often considered "masculine men" and females were "feminine women" (these binary pairings are referred to as "cis gendered") (West \& Zimmerman, 1987). However, there is currently a movement away from these restricted binary sets into more individualistic sets of categories based on the individual's cultural and social norms (West \& Zimmerman, 1987).

Gender is defined as the adherence to non-physiological characteristics, behaviors, and attitudes that an individual's culture deems appropriate for the individual's sex category (Pentony, 1980; West \& Zimmerman, 1987). Bem (1974) has put forward a measure to determine whether a person adheres to the category aligned with his or her sex (sex-typed; i.e., masculine men), aligned with the opposite category (cross-sex-typed; i.e., feminine men), aligned with both (androgynous; i.e., a man who is both masculine and feminine) or neither (undifferentiated; i.e., a man who is neither masculine nor feminine). The current study categorizes gender using these four categories (masculine, feminine, androgynous, and undifferentiated) and measures how strongly a person adheres to each of the categories but does not take into account whether the gender aligns with a person's identified sex. 
Unlike sex, gender adherence has been demonstrated to be a reliable predictor of several dimensions of attitudes regarding mental illness. Hinkelman and Granello (2003) surveyed individuals using the Hypergender Ideology Scale (Hamburger, Hogben, McGowan, \& Dawson, 1996), which measures individuals' strength of adherence to traditional gender roles (e.g., how strongly a male adheres to the masculine gender). The authors suggested that more rigid adherence to one's gender is related to less tolerant attitudes toward mental illness but did not conduct statistical analyses to substantiate this claim. Kivari (2009) did affirm this suggestion when measuring gender as a predictor of attitudes toward mental illness. In Kivari's (2009) study, positive attitudes toward mental illness were defined as treatability (of mental disorders), professional efficacy (defined as the confidence in mental health professionals), and recovery (defined as the expectations/beliefs about the likelihood of recovery); negative attitudes were defined as anxiety (e.g., "I feel anxious and uncomfortable when I'm around someone with depression."), relationship disruption (e.g., "Depression prevents people from having normal relationships with others."), hygiene (e.g., "People with depression ignore their hygiene such as bathing and using deodorant."), and visibility (e.g., "I can tell that someone has depression by the way he or she talks."). The results of the study showed that adherence to feminine gender was a robust predictor of positive attitudes toward mental illness, and adherence to masculine gender was a robust predictor of negative attitudes toward mental illness. 


\section{Sex and Gender as Predictors of Attitudes Toward Persons With Mental Illness}

The inconsistent findings regarding sex and the reliable findings from studies that measure gender separately from sex are possibly due to the tendency of researchers examining this topic to utilize the terms "gender" and "sex" interchangeably or otherwise not adequately differentiate the terms for participants. In other words, many researchers have treated an individual's sex as interchangeable with gender rather than as a separate concept (Arora, Metz, \& Carlson, 2016; Artis, 1997; Hampton \& Sharp, 2014; Leong \& Zachar, 1999; Madianos, Zartaloudi, Alevizopoulos, \& Katostaras, 2011; Wendt \& Shafer, 2016). Consequently, sex and gender are often undifferentiated in the scientific literature, creating difficulties drawing concrete conclusions from these studies. Because few studies on this topic differentiate sex and gender in both conceptualization and methodology, available literature in this area is sparse.

Only one published article has separated sex and gender in the same study (Hinkelman \& Granello, 2003). More specifically, this study differentiated the two constructs as separate predictors of attitudes toward mental illness. The authors defined gender role as "the [traditional and culturally-specific] way in which others interact with and teach the individual how to be appropriately male or female" (p. 260). Strong adherence to one's gender role was called "hypergender," and beliefs and attitudes specific to hypergender roles were called "hypergender ideology." Further, Hinkelman and Granello elaborated that "inherent in the hypergender construct is a belief that others should behave in certain socially prescribed ways" (p. 261) and stated that this could result in a lower tolerance of individuals who behave in socially deviant ways. One such 
area of lowered tolerance, according to the authors, could encompass individuals with mental illness, who are traditionally seen as socially deviant from the norm.

The purpose of the Hinkelman and Granello (2003) study was to address a gap in the literature in which previous researchers examined attitudes using only the dichotomous variable "sex" and did not take into account the effect of gender on attitudes and perceptions. The authors investigated whether attitudes toward people with mental illness differed significantly between sexes and if sex explained differences in attitudes toward people with mental illness after controlling for the strength of adherence to traditional gender norms. Hinkelman and Granello's first hypothesis stated that there would be "differences in self-reported tolerance toward persons with mental illness based on the...sex of the participant" (p. 261) but did not specify what would be these differences. Their second hypothesis was that "when adherence to hypergender ideology is used as a covariate, there will be differences in self-reported tolerance toward persons with mental illness, based on the...sex of the participant" but again did not specify what would be these differences (p. 262). The authors noted that they expected that the null hypothesis for their second hypothesis would be rejected due to the "notion that sex is not sufficient for examining these attitudes" (p. 262).

The independent variables in Hinkelman and Granello's (2003) study were participants' sex and gender role adherence. Gender role adherence was measured by the Hypergender Ideology Scale (Hamburger et al., 1996), which separates the construct into two dimensions: masculinity and femininity. The hypermasculinity scale measured men's beliefs regarding personality characteristics such as "aggressive beliefs about entitlement 
to sex, negative attitudes toward women, an increased propensity toward violence (particularly sexual violence), and perception that danger is exciting" (Hamburger et al., 1996, p. 265). The hyperfemininity scale measured women's beliefs regarding traditional and stereotypic feminine gender roles. According to the authors, "hyperfeminine women believe that their ability to be successful is based on their relationships with men, they view their physical appearance and sexuality as of paramount importance in romantic relationships, and they hold the expectations that men will adhere to traditional male gender roles" (p. 265). The dependent variable was the individual's attitudes toward mental illness, measured by the four dimensions of the CAMI scale (CAMI; Taylor \& Dear, 1981).

To test their first research hypothesis, Hinkelman and Granello (2003) conducted a multivariate analysis of variance (MANOVA) to analyze CAMI scale differences using sex as the independent variable. The results of the MANOVA showed that males were significantly less benevolent and more socially restrictive than females, supporting the first hypothesis. However, conclusions could not be drawn regarding whether the less tolerant beliefs were by males were due to sex or hypergender ideology. Therefore, the authors tested their second hypothesis by conducting a multivariate analysis of covariance (MANCOVA) to test the effect of sex after controlling for gender role adherence. They found that, after controlling for gender role adherence, sex did not have a significant effect on any of the CAMI subscale scores; thus, the second hypothesis was not supported. 
Although authors stated in their introduction that adherence to a gender role ideology was related to attitudes and their findings suggest that gender role adherence was a significant predictor of attitudes above and beyond sex, they did not statistically control for sex in their study to bolster this claim, instead relying only on correlation analysis. The researchers did not test for an effect of gender role adherence on their dependent variable. The statistical analyses were insufficient to truly understand the effect of gender role adherence on attitudes toward persons with mental illness. The findings of Hinkelman and Granello (2003) therefore limit what can be said of the relationship between sex, gender, and these attitudes, which is especially concerning due to the argument present in their introduction that outlined how gender might explain differences in attitudes when sex was an inconsistent predictor. More rigorous analyses would help improve our understanding of these variables and open new paths to study how persons with mental illness are viewed by others. The current study examines both sex and gender as separate predictors and examines whether gender is a significant predictor of attitudes after controlling for sex. Conducting these additional analyses can help determine whether there is no effect of gender or whether an effect of gender is so strong that sex does not have predictive ability above and beyond gender.

Another limitation of the Hinkelman and Grandllo (2003) study pertains to the methodology utilized. The authors cite the gender role adherence scale used in this study, the Hypergender Ideology Scale, as a possible limitation of the investigation, suggesting that participants may have responded in socially desirable ways. The items on the scale focus on sexual activities, dating, substance use, homophobia, and sexual assault which is 
problematic for two main reasons. First, the content may encourage participants to respond in a socially desirable way. Second, the scale may be too limited in the scope of content they are measuring (i.e., a participant may have never been sexually active), making it difficult for respondents who have not experienced the content of the items to respond. The narrow scope of content neglects that gender relates to a wide range of behaviors, attitudes, and characteristics. As West and Zimmerman (1987, p. 130) note, "gender is not merely something that happens in the nooks and crannies of interaction, fitted in here and there and not interfering with the serious business of life."

The Hypergender Ideology Scale may fail to provide insight into behaviors, attitudes and characteristics thought to be gender-related such as leadership, sympathy, loyalty, independence, or self-reliance (Ballard-Reisch \& Elton, 1992; Bem, 1974). Alternative scales could be utilized to determine whether individuals endorse a wider variety of domains as part of their gender role adherence. Bem (1974) provided such an instrument with the well-validated self-report scale Bem Sex Role Inventory (BSRI). Items in this scale were presented in a neutral way and with other items that were not explicitly gender-coded but which fall into traditional gender role ideologies. Because the BSRI, unlike the Hypergender Ideology Scale, does not use explicit gendered terms or language and scenarios that potentially prompt socially desirable responses, it encourages participants to respond truthfully and report how well the items describe them. Therefore, the current study utilizes the BSRI to measure how strongly an individual adheres to his or her traditional gender role and categorize participants into the four corresponding groups: masculine, feminine, androgynous, and unclassified. 


\section{The Current Study}

Prior researchers report that sex is an inconsistent predictor of attitudes (Hampton \& Sharp, 2014; Hinkelman \& Granello, 2003; Kivari, 2009; Wendt \& Shafer, 2016) and does not explain attitude differences above and beyond the effect of gender role adherence (Hinkelman \& Granello, 2003). Hinkelman and Granello (2003) specifically suggested that males with a strong gender role adherence are less benevolent and less socially restrictive than are females of any gender role adherence. However, the authors failed to conduct sufficient statistical analyses to determine with certainty whether this finding was due to sex or to gender.

Previous researchers have also found that gender role adherence explained differences in attitudes above and beyond the effect of sex (Kivari, 2009). More specifically, adherence to feminine gender was more strongly related to positive attitudes and adherence to masculine gender was more strongly related to negative attitudes (Kivari, 2009). However, the scale utilized in this study was limited in scope such that it only measured dating relationships, substance use, and assault, thus omitting alternative dimensions of gender role adherence that would provide insight to the expression, attitudes, or performance of gender outside of those three areas.

The purpose of the current study addresses whether attitudes toward persons with mental illness differ depending on a person's sex and gender role adherence. This study also aims to assess whether sex or gender is a more reliable predictor of these attitudes. The current study addresses two major literature gaps: statistical analyses assessing the relationship between the three main variables (sex, gender role adherence, and attitudes 
toward persons with mental illness) and the scales utilized in previous studies to measure the construct of gender role adherence. The following hypotheses are tested in this study: Hypothesis 1: Sex will be significantly related to attitudes toward persons with a mental illness such that males will hold more negative attitudes (more authoritative, less benevolent, more socially restrictive, and more negative community mental health ideology) than will females.

Hypothesis 2: Gender adherence will be significantly related to attitudes toward persons with a mental illness such that those who adhere more strongly to masculine gender roles will hold more negative attitudes (more authoritative, less benevolent, more socially restrictive, and more negative community mental health ideology) than will those who adhere more strongly to feminine gender roles. No hypotheses will be made regarding those who adhere to neither gender role nor regarding those who adhere strongly to both gender roles, although these relationships will be examined in the current study.

Hypothesis 3: When statistically controlling for gender role adherence, sex will not explain differences in attitudes toward persons with a mental illness above and beyond the effect of gender role adherence.

Hypothesis 4: When statistically controlling for sex, gender role adherence will explain differences in attitudes toward persons with a mental illness above and beyond the effect of sex. 


\section{Method}

\section{Participants}

A total of 209 individuals participated in this study. Data were collected during the spring of 2019 using social networking sites (e.g., Facebook), and by recruiting college students at San José State University (SJSU). Approximately 60\% of the respondents were from social networking sites and $40 \%$ were SJSU students. Because this study aimed to assess attitudes toward individuals with a mental illness, participants were not recruited from populations known to have strong attitudes toward mental illness (e.g., psychology majors) so as to not bias the collected data. Twenty-two response sets were removed due to lack of completion, and the response sets from participants who selfidentified as being outside the male-female binary were removed due the nature of the analyses requiring robust group membership representation. The final sample consisted of 187 participants.

Table 1 reports demographic information of the sample. Among the participants, 67 (35.8\%) were male, $118(63.1 \%)$ were female, and two (1.1\%) were transsexual male-tofemale (MtF) . Among those who self-reported their identified gender, $116(62.0 \%)$ were female, $66(35.3 \%)$ were male, two $(1.1 \%)$ were non-binary or genderqueer, one $(0.5 \%)$ was genderfluid (i.e., identification with a gender category changes over time), one $(0.5 \%)$ was agender (i.e., identifying as no gender), and one $(0.5 \%)$ was transgender (e.g., an individual whose sex is male and whose gender is female). Among those who selfreported their identified sexual orientation, 161 (86.1\%) identified as straight, 17 (9.1\%) were bisexual, five (2.7\%) were asexual (i.e., experiencing little or no sexual attraction to 
anyone), two (1.1\%) were gay or lesbian, one $(0.5 \%)$ was demisexual (i.e., only experiences attraction when there is an established social connection to another person), and one $(0.5 \%)$ was sapiosexual (i.e., an attraction to an intelligent person). Participant ages ranged from 18 years old to 83 years old, with a mean age of 27 years old $(S D=$ 13.53). Most participants ( $75 \%)$ were 28 years old or younger.

Table 1

Demographic Characteristics of Participants $(N=187)$

\begin{tabular}{lrr}
\hline Variable & $n$ & $\%$ \\
\hline Sex & & \\
Female & 118 & 63.1 \\
Male & 67 & 35.8 \\
Other & 2 & 1.1 \\
Gender & 1 & \\
Agender & 116 & 0.5 \\
Female & 1 & 62.0 \\
Genderfluid & 66 & 0.5 \\
Male & 2 & 35.3 \\
Nonbinary or Genderqueer & 1 & 1.1 \\
Transgender & & 0.5 \\
Sexual Orientation & 5 & \\
Asexual & 17 & 2.7 \\
Bisexual or Pansexual & 1 & 9.7 \\
Demisexual & 2 & 0.5 \\
Gay or Lesbian & 1 & 1.1 \\
Sapiosexual & 161 & 0.5 \\
Straight & & 86.1 \\
\hline
\end{tabular}

\section{Measures}

Attitudes toward persons with mental illness. Attitudes toward persons with a mental illness were measured with the Community Attitudes toward Mentally Ill Scale (Taylor \& Dear, 1981). This 40-item scale assesses laypersons' attitudes toward individuals with mental illness on four dimensions: authoritarianism, benevolence, social 
restrictiveness, and community mental health ideology. Although the original CAMI form consisted of 40 items (Taylor \& Dear, 1981), the survey was reduced to 23 items due to a lack of item reliability reported in various studies that utilized the instrument (Brockington, Hall, Levings, \& Murphy, 1993; Högberg, Magnusson, Ewertzon, \& Lützén, 2008; Morris, et al., 2012; Wolff, Pathare, Craig, \& Leff, 1996). Respondents rated how much they agreed or disagreed with various statements regarding individuals with mental illness and community resources for the mentally ill. The items had a 5-point Likert scale agreement response format $(1=$ strongly agree, $2=$ disagree, $3=$ neutral, $4=$ agree, and $5=$ strongly agree). The responses to the items in each subscale were averaged and a composite score was created to determine an overall attitude dimension score for each participant; the higher the score, the more positive the individual's attitude toward the mentally ill. The possible range for scores was 1 to 5 . Thus, a score closer to 1 indicated a negative attitude and a score closer to 5 indicated a positive attitude for that particular dimension.

Authoritarianism is the belief of the inferiority of persons with mental illness and the belief that persons with mental illness are fundamentally different from the general population. This subscale consisted of six items. Examples of items representing authoritarianism include, "One of the main causes of mental illness is a lack of selfdiscipline and will power" and "Mental patients need the same kind of control and discipline as a young child." Initially, higher scores of items in this scale indicated a negative attitude and lower scores indicated a positive attitude; the items were recoded in analyses such that lower scores indicated negative attitudes and higher scores indicated 
positive attitudes. The internal consistency reliability of the authoritarianism subscale $($ Cronbach's alpha $=.73)$ was considered to be acceptable (Nunnally, 1978).

Benevolence is defined as sympathetic cognitions regarding mental illness and persons with mental illness. This subscale consisted of five items. Examples of items representing benevolence include, "We need to adopt a far more tolerant attitude toward the mentally ill in our society" and "More tax money should be spent on the care and treatment of the mentally ill." Lower scores indicated negative attitudes and higher scores indicated positive attitudes on this dimension. The internal consistency reliability of the benevolence subscale $($ Cronbach's alpha $=.80)$ was considered to be acceptable (Nunnally, 1978).

Social restrictiveness is the belief that persons with mental illness are a societal threat and that one should maintain social distance or reduce social closeness with them. This subscale consisted of four items. Examples of items representing social restrictiveness include, "I would not want to live next door to someone who has been mentally ill" and "The mentally ill should be isolated from the rest of the community." Initially, higher scores of items in this scale indicated a negative attitude and lower scores indicated a positive attitude; the items were recoded in analyses such that lower scores indicated negative attitudes and higher scores indicated positive attitudes. The internal consistency reliability of the social restrictiveness subscale (Cronbach's alpha $=.68$ ) was considered to be somewhat low (Nunnally, 1978).

Community mental health ideology are beliefs regarding the effect of integrating persons with mental illness into one's geographical and social community. There were 
eight items in this subscale. Examples of items representing community mental health ideology include, "Residents have nothing to fear from people coming into their neighborhood to obtain mental health services" and "Locating mental health facilities in a residential area downgrades the neighborhood" (reverse scored). Lower scores indicated negative attitudes and higher scores indicated positive attitudes on this dimension. The internal consistency reliability of the community mental health ideology subscale $($ Cronbach's alpha $=.88)$ was considered to be acceptable (Nunnally, 1978).

Gender role adherence. Gender role adherence was measured using Bem's Sex Role Inventory short form (BSRI; Bem, 1974). This 30-item scale measures participants' adherence to various traditional gender-specific characteristics. Items on this survey are coded as "masculine," "feminine," or "neutral" (i.e., filler items that are neither masculine nor feminine and intended to disguise the other two types of items) using normalized data. Five neutral items were removed to reduce the length of the survey, leaving a total of 10 masculine items, 10 feminine items, and five neutral items. The scale utilizes a 7point response format $(1=$ Almost never true, $2=$ rarely true, $3=$ true less than half the time, $4=$ neutral, $5=$ true more than half the times, $6=$ often true, $7=$ almost always true).

Masculinity is defined as the extent to which an individual adheres to characteristics, behaviors, and attitudes that an individual's culture determines are aligned with the male sex category. Examples of items representing masculinity include "self-sufficient" and "dominant." The average response of the masculine items was calculated into a "masculinity score" for each participant. Higher scores indicated a stronger adherence to 
a masculine gender. The internal consistency reliability of the masculinity score $(\alpha=.81)$ was considered to be acceptable (Nunnally, 1978).

Femininity is defined as the extent to which an individual adheres to characteristics, behaviors, and attitudes that an individual's culture determines are aligned with the female sex category. Examples of items representing femininity include "compassionate" and "gentle." The average response of the feminine items was calculated into a "femininity score" for each participant. Higher scores indicated a stronger adherence to a feminine gender. The internal consistency reliability of the femininity score (Cronbach's alpha $=.87$ ) was considered to be acceptable (Nunnally, 1978).

Participants were then categorized depending on whether they scored higher or lower than the median for the respective masculinity or femininity gender role adherence score. Individuals whose masculinity score was above the median of the masculine score but whose femininity score was below the median of the femininity items were categorized as adhering to a masculine gender. Individuals whose masculinity score was below the median of the masculine score but whose femininity score was above the median of the femininity items were categorized as adhering to a feminine gender. Individuals who scored above both medians were categorized as "androgynous" (adhering to both masculine and feminine genders); individuals who scored below both medians were categorized as "undifferentiated" (adhering to neither masculine nor feminine genders; participants in this category are considered to have low gender role adherence relative to the other categories). The gender adherence categories of the current study's sample 
consisted of $71(38.4 \%)$ androgynous, $56(30.3 \%)$ undifferentiated, 30 (16.2\%) feminine, and $28(15.1 \%)$ masculine participants (two participants did not respond to these items).

Demographics. Demographics were obtained with six items. These items were age, sex, gender, and sexual orientation. The items were chosen to determine the composition of the sample and its representation of the general population, and to disguise the item requesting participants' sex so as to not prime the participants regarding the nature of the study.

\section{Procedure}

Data were collected using an online survey set up in Qualtrics. The online survey was posted to social networking forums, eliciting participants to voluntarily select the link to a survey measuring attitudes toward persons with a mental illness and gender adherence. The survey was also posted on a university website wherein students enrolled in introductory psychology courses at SJSU during the spring of 2019 could access the survey. These participants were required to participate in psychological research using the university's online portal where they could choose which study they wished to do; the current study's survey was listed among the options and credit was granted for participants who completed the study, per course guidelines.

In both data collection methods, the researcher informed the participants that the survey measured attitudes toward individuals with mental illness and that participants did not need to have experienced mental illness personally, nor did they need to have experience interacting with mentally ill persons. Participants learned that their participation in the study was completely voluntary and that all of the data would be 
confidential. Following this explanation, the participants accessed the questionnaires consisting of two scales measuring community attitudes toward the mentally ill and gender adherence. Once all surveys were finished, the data were entered into SPSS Version 24 for statistical analysis. 


\section{Results}

\section{Descriptive Statistics}

Table 2 presents descriptive statistics for the four dimensions of attitudes towards individuals with a mental illness. As noted above, items on the Authoritarianism and Social Restrictiveness subscales were reverse coded such that higher responses indicated more positive attitudes and lower responses indicated more negative attitudes.

Of the four dimensions, the benevolent subscale had the most positive responses $(M=$ $4.26, S D=.62)$. Responses to items in this dimension suggest that participants regarded persons with mental illness with sympathy. Community Mental Health Ideology (CMHI) had the lowest positive responses $(\mathrm{M}=3.79, \mathrm{SD}=.66)$. However, participants still generally indicated positive attitudes on this dimension. Both authoritarianism and social restrictiveness subscales had relatively high averages, indicating that the participants did not report high authoritarianism and social restrictiveness.

Table 2

Descriptive Statistics and Bivariate Correlations, CAMI Subscales $(n=185)$

\begin{tabular}{|c|c|c|c|c|c|c|c|c|c|}
\hline Dimension & $M$ & $S D$ & 1 & & 2 & & 3 & & 4 \\
\hline Authoritarianism & 3.94 & .61 & -- & & & & & & \\
\hline Benevolence & 4.26 & .62 & .63 & $* * *$ & -- & & & & \\
\hline Social Restrictiveness & 3.83 & .67 & .65 & $* * *$ & .63 & $* * *$ & -- & & \\
\hline CMHI & 3.79 & .66 & .69 & $* * *$ & .55 & $* * *$ & .71 & $* * *$ & -- \\
\hline
\end{tabular}

\section{Correlations}

A Pearson correlation analysis was conducted on the variables to assess the relationships among the CAMI subscales. Correlations are displayed in Table 2. The subscales were highly and significantly positively correlated with each other, indicating 
that if a participant had a positive attitude on one dimension, they were very likely to have a positive attitude on the other dimensions. Social Restrictiveness and CMHI had a particularly high correlation $(r=.71, p<.01)$, which suggests that the less socially restrictive an individual, the more positively they view community services and supports for persons with a mental illness. Moreover, this strong correlation could indicate that measuring both dimensions may not provide substantially more information than measuring one dimension that encompasses both sets of items.

\section{Sex Differences}

The next set of analyses addressed the first hypothesis: do attitudes toward individuals with mental illness differ by sex? Four two-sample t-tests were conducted to determine whether there was a difference in attitudes toward individuals with mental illness depending on the sex of participants. Table 3 shows the results of the t-tests. There were no significant differences between sexes on any of the dimensions. These results showed that attitudes toward persons with a mental illness did not differ by sex, and therefore, the first hypothesis was not supported.

\section{Table 3}

Community Attitudes Toward the Mentally Ill by Sex

\begin{tabular}{lccccc}
\hline & \multicolumn{3}{c}{ Sex } \\
& \multicolumn{2}{c}{ Female $(n=118)$} & \multicolumn{2}{c}{ Male $(n=67)$} & \\
\cline { 2 - 5 } & $\mathrm{M}$ & $\mathrm{SD}$ & $\mathrm{M}$ & $\mathrm{SD}$ & $\mathrm{t}$ \\
\hline Authoritarianism & 3.95 & .61 & 3.79 & .61 & -.41 \\
Benevolence & 4.31 & .61 & 4.16 & .68 & -1.57 \\
Social Restrictiveness & 3.88 & .67 & 3.74 & .67 & -1.36 \\
CMHI & 3.80 & .70 & 3.78 & .60 & -.22 \\
\hline Note: $* p<.05, * * p<.01, * * * p<.001$ & & &
\end{tabular}




\section{Gender Role Adherence Differences}

The next set of analyses addressed the second hypothesis: do attitudes toward individuals with mental illness differ by gender adherence? Four one-way analyses of variance (ANOVA) were run to determine if the means of the each of the CAMI dimensions significantly differed across gender adherence categories. The results of the one-way ANOVAs (Table 4) showed that participants did not differ based on gender adherence on three dimensions: Authoritarianism, $F(3,181)=1.52, p>.05$; Social Restrictiveness, $F(3,181)=1.78, p>.05$; and CMHI, $F(3,181)=1.78, p>.05$. Participants demonstrated significant differences in benevolent attitudes based on gender adherence, $F(3,181) 4.75, p<.01$. Tukey post hoc comparisons were conducted to examine group differences.

Table 4

Means, Standard Deviations, and One-Way Analysis of Variance (ANOVAs) for Effect on Gender Adherence on Attitudes Toward Individuals With Mental Illness

\begin{tabular}{|c|c|c|c|c|c|c|c|c|c|}
\hline \multirow[t]{2}{*}{ Variable } & \multicolumn{2}{|c|}{$\begin{array}{l}\text { Androgynous } \\
(n=71)\end{array}$} & \multicolumn{2}{|c|}{$\begin{array}{l}\text { Feminine } \\
(n=30)\end{array}$} & \multicolumn{2}{|c|}{$\begin{array}{l}\text { Masculine } \\
(n=28)\end{array}$} & \multicolumn{2}{|c|}{$\begin{array}{l}\text { Undiff. } \\
(n=56)\end{array}$} & \multirow{2}{*}{$\frac{\text { ANOVA }}{\mathrm{F}(3,181)}$} \\
\hline & $\mathrm{M}$ & SD & $\mathrm{M}$ & SD & $\mathrm{M}$ & SD & $\mathrm{M}$ & SD & \\
\hline Authoritarianism & 3.74 & .62 & 4.10 & .56 & 3.90 & .54 & 3.82 & .64 & 1.52 \\
\hline Benevolence & 4.32 & .57 & 4.47 & .41 & 4.33 & .72 & 4.01 & .66 & $4.78^{* *}$ \\
\hline $\begin{array}{l}\text { Social } \\
\text { Restrictiveness }\end{array}$ & 3.87 & .71 & 4.03 & .68 & 3.76 & .63 & 3.71 & .63 & 1.78 \\
\hline CMHI & 3.78 & .64 & 4.04 & .63 & 3.74 & .81 & 3.70 & .62 & 1.78 \\
\hline
\end{tabular}

The comparisons revealed that Feminine participants held significantly more benevolent attitudes $(M=4.47)$ than did Undifferentiated participants $(M=4.01)$. 
Overall, authoritarianism, social restrictiveness, and community mental health ideology attitudes did not differ by gender role adherence, whereas participants who endorsed feminine gender norms had significantly more benevolent attitudes toward persons with a mental illness than did participants with undifferentiated gender role. Therefore, the second hypothesis is partially supported.

\section{Hierarchical Multiple Regression}

The next set of analyses addressed the third hypothesis: does sex explain attitudes toward individuals with mental illness above and beyond the effects of gender adherence? To test the third hypothesis, four hierarchical multiple regression analyses were conducted to determine if sex could predict attitudes toward individuals with a mental illness when controlling for gender adherence. Because gender adherence was a categorical variable with four groups, the categories were recoded into three new variables using effect coding to represent those four gender adherence categories. In these four analyses, gender adherence was entered first, then sex to test the incremental effect of sex.

In the first analysis, the variables representing gender adherence were entered in the first step to account for their variance in authoritarian attitudes. As presented in Table 5, there was not a significant effect of gender adherence on authoritarianism, $R^{2}=.03, R^{2}$ adj $=.01, F(3,181)=1.52, p>.05$. Sex was then entered in the second step to determine if sex could predict authoritarianism over and above the effect of gender adherence. There was not a significant incremental effect of sex on authoritarianism, $\Delta \mathrm{R}^{2}=.00, F(1,180)$ $=.00, p>.05$. 
Table 5

Hierarchical Multiple Regression Testing the Incremental Effect of Sex Over and Above the Effect of Gender Adherence on Authoritarianism $(N=185)$

\begin{tabular}{|c|c|c|c|}
\hline Variable & B & $\mathrm{R}^{2}$ & $\Delta \mathrm{R}^{2}$ \\
\hline Step1: Gender Adherence & & .03 & -- \\
\hline Androgynous & .03 & & \\
\hline Male & -.48 & & \\
\hline Female & .17 & & \\
\hline Step 2: Sex & & .03 & .00 \\
\hline Sex & .00 & & \\
\hline
\end{tabular}

In the second analysis, the variables representing gender adherence were entered in the first step to account for their variance in benevolent attitudes. As presented in Table 6 , there was a significant effect of gender adherence on benevolence, $R^{2}=.07, R^{2}$ adj $=$ $.06, F(3,181)=4.75, p<.05$. Only adherence to a feminine gender significantly contributed to the variance in benevolence, $\beta=.20, t=2.05, p<.05$, indicating that participants who adhered to a feminine gender held significantly more benevolent attitudes relative to the other gender adherence categories. Sex was then entered in the second step to determine if sex could predict benevolence over and above the effect of gender adherence. There was not a significant incremental effect of sex on benevolence, $\Delta \mathrm{R}^{2}=.01, F(1,180)=1.07, p>.05$ 
Table 6

Hierarchical Multiple Regression Testing the Incremental Effect of Sex Over and Above the Effect of Gender Adherence on Benevolence $(N=185)$

\begin{tabular}{|c|c|c|c|}
\hline Variable & $\mathrm{B}$ & $\mathrm{R}^{2}$ & $\Delta \mathrm{R}^{2}$ \\
\hline Step1: Gender Adherence & & $.07 * *$ & -- \\
\hline Androgynous & .06 & & \\
\hline Masculine & .05 & & \\
\hline Feminine & $.20 *$ & & \\
\hline \multirow[t]{2}{*}{ Step 2: Sex } & & .08 & .01 \\
\hline & .08 & & \\
\hline
\end{tabular}

In the third analysis, the variables representing gender adherence were entered in the first step to account for their variance in socially restrictive attitudes. As presented in

Table 7, there was not a significant effect of gender adherence on social restrictiveness, $\mathrm{R}^{2}=.029, \mathrm{R}^{2}$ adj $=.01, F(3,181)=1.78, p>.05$. Sex was then entered in the second step to determine if sex could predict social restrictiveness over and above the effect of gender adherence. There was not a significant incremental effect of sex on social restrictiveness, $\Delta \mathrm{R}^{2}=.005, F(1,180)=.99, p>.05$.

Table 7

Hierarchical Multiple Regression Testing the Incremental Effect of Sex Over and Above the Effect of Gender Adherence on Social Restrictiveness $(N=185)$

\begin{tabular}{|c|c|c|c|}
\hline Variable & B & $\mathrm{R}^{2}$ & $\Delta \mathrm{R}^{2}$ \\
\hline Step1: Gender Adherence & & .029 & -- \\
\hline Androgynous & .04 & & \\
\hline Masculine & -.08 & & \\
\hline Feminine & .19 & & \\
\hline \multirow[t]{2}{*}{ Step 2: Sex } & & .034 & .005 \\
\hline & .07 & & \\
\hline
\end{tabular}


In the fourth analysis, the variables representing gender adherence were entered in the first step to account for their variance in Community Mental Health Ideology. As presented in Table 8, there was not a significant effect of gender adherence on CMHI, $\mathrm{R}^{2}$ $=.03, F(3,181)=1.78, p>.05$. Sex was then entered in the second step to determine if sex could predict CMHI over and above the effect of gender adherence. There was not a significant incremental effect of sex on CMHI, $\Delta \mathrm{R}^{2}=.00, F(1,180)=.02, p>.05$.

Table 8

Hierarchical Multiple Regression Testing the Incremental Effect of Sex Over and Above the Effect of Gender Adherence on Community Mental Health Ideology $(N=185)$

\begin{tabular}{cccc} 
Variable & $\beta$ & $\mathrm{R}^{2}$ & $\Delta \mathrm{R}^{2}$ \\
\hline Step1: Gender Adherence & & .03 & -- \\
Androgynous & -.05 & & \\
Masculine & -.07 & & \\
Feminine & .22 & &
\end{tabular}

Step 2: Sex

Feminine

.03

.00

$\frac{\operatorname{Sex}}{\text { Note: } * \mathrm{p}<.05, * * \mathrm{p}<.01, * * * \mathrm{p}<.001}$

$-.01$

The final set of analyses addressed the fourth hypothesis: does gender adherence explain attitudes toward individuals with mental illness above and beyond the effects of sex? To test the fourth hypothesis, four hierarchical multiple regression analyses were conducted to determine if gender adherence could predict attitudes toward individuals with a mental illness when controlling for sex.

In the first analysis, sex was entered in the first step to account for its variance in authoritarian attitudes. As presented in Table 9, there was not a significant effect of sex on authoritarianism, $\mathrm{R}^{2}=.001, \mathrm{R}^{2}$ adj $=-.01, F(1,183)=.17, p>.05$. The variables representing gender adherence were entered in the second step to determine if gender 
adherence could predict attitudes over and above the effect of sex. There was not a significant incremental effect of gender adherence on authoritarianism, $\Delta \mathrm{R}^{2}=.024, F(3$, $180)=1.46, p>.05$.

Table 9

Hierarchical Multiple Regression Testing the Incremental Effect of Gender Adherence Over and Above the Effect of Sex on Authoritarianism $(N=185)$

\begin{tabular}{|c|c|c|c|}
\hline Variable & $\beta$ & $\mathrm{R}^{2}$ & $\Delta \mathrm{R}^{2}$ \\
\hline Step1: Sex & & .001 & -- \\
\hline Sex & .03 & & \\
\hline Step 2: Gender Adherence & & .025 & .024 \\
\hline Androgynous & .03 & & \\
\hline Masculine & -.05 & & \\
\hline Feminine & .17 & & \\
\hline
\end{tabular}

Note: $* p<.05, * * p<.01, * * * p<.001$

In the second analysis, sex was entered in the first step to account for its variance in benevolent attitudes. There was not a significant effect of sex on benevolence, $\mathrm{R}^{2}=.01$, $\mathrm{R}^{2}$ adj $=.01, F(1,183)=2.47, p>.05$. As presented in Table 10, the variables representing gender adherence were entered in the second step to determine if gender adherence could predict benevolence over and above the effect of sex. There was a significant incremental effect of gender adherence on benevolence, $\Delta \mathrm{R}^{2}=.07, F(3,180)=4.24, p<.05$. However, no particular gender category significantly contributed to benevolent attitudes above and beyond the effect of sex. 
Table 10

Hierarchical Multiple Regression Testing the Incremental Effect of Gender Adherence Over and Above the Effect of Sex on Benevolence $(N=185)$

\begin{tabular}{|c|c|c|c|}
\hline Variable & $\beta$ & $\mathrm{R}^{2}$ & $\Delta \mathrm{R}^{2}$ \\
\hline Step1: Sex & & .01 & -- \\
\hline Sex & .12 & & \\
\hline Step 2: Gender Adherence & & $.08 * *$ & .07 \\
\hline Androgynous & .05 & & \\
\hline Masculine & .05 & & \\
\hline Feminine & .19 & & \\
\hline
\end{tabular}

In the third analysis, sex was entered in the first step to account for its variance in socially restrictive attitudes. There was not a significant effect of sex on social restrictiveness, $\mathrm{R}^{2}=.01, \mathrm{R}^{2}$ adj $=.01, F(1,183)=1.85, p>.05$. As presented in Table 11, the variables representing gender adherence were entered in the second step to determine if gender adherence could predict social restrictiveness over and above the effect of sex. There was not a significant incremental effect of gender adherence on social restrictiveness, $\Delta \mathrm{R}^{2}=.02, F(3,180)=1.49, p>.05$.

Table 11

Hierarchical Multiple Regression Testing the Incremental Effect of Gender Adherence Over and Above the Effect of Sex on Social Restrictiveness $(N=185)$

\begin{tabular}{|c|c|c|c|}
\hline Variable & $\beta$ & $\mathrm{R}^{2}$ & $\Delta \mathrm{R}^{2}$ \\
\hline Step1: Sex & & .01 & -- \\
\hline Sex & .10 & & \\
\hline Step 2: Gender Adherence & & .03 & .02 \\
\hline Androgynous & .04 & & \\
\hline Masculine & -.08 & & \\
\hline Feminine & .18 & & \\
\hline
\end{tabular}


In the fourth analysis, sex was entered in the first step to account for its variance in Community Mental Health Ideology. As presented in Table 12, there was not a significant effect of sex on CMHI, $\mathrm{R}^{2}=.00, \mathrm{R}^{2}$ adj $=.00, F(1,183)=.05, p>.05$. The variables representing gender adherence were entered in the second step to determine if gender adherence could predict CMHI over and above the effect of sex. There was not a significant incremental effect of gender adherence on $\mathrm{CMHI}, \Delta \mathrm{R}^{2}=.03, F(3,180)=1.76$, $p>.05$.

Table 12

Hierarchical Multiple Regression Testing the Incremental Effect of Gender Adherence Over and Above the Effect of Sex on Community Mental Health Ideology $(N=185)$

\begin{tabular}{|c|c|c|c|}
\hline Variable & $\beta$ & $\mathrm{R}^{2}$ & $\Delta \mathrm{R}^{2}$ \\
\hline Step1: Sex & & .00 & -- \\
\hline Sex & .02 & & \\
\hline Step 2: Gender Adherence & & .03 & .03 \\
\hline Androgynous & -.04 & & \\
\hline Masculine & -.07 & & \\
\hline Feminine & .22 & & \\
\hline
\end{tabular}

\section{Summary}

In summary, the first hypothesis was not supported, and the second and third hypotheses were only partially supported. The $t$-tests results showed that attitudes towards individuals with a mental illness did not significantly differ between sexes, thereby not supporting the first hypothesis. The results of the ANOVAs showed that attitude differences were present only between participants who did not endorse genderspecific items and participants adhering to a feminine gender, such that participants adhering to a feminine gender held more benevolent attitudes toward persons with mental 
illness than did undifferentiated participants. There were no significant differences between genders on authoritarianism, social restrictiveness, and community mental health ideology. The results of the ANOVAs provide partial support for the second hypothesis.

Further, the results of the hierarchical multiple regression analyses showed that adherence to a feminine gender role contributed to variance in benevolent attitudes; however, there were no significant incremental effects of sex over and above the effects of gender adherence on all four attitude dimensions. Therefore, hypothesis 3 was supported. Further, there were no significant incremental effects of gender adherence over and above the effects of sex on authoritarianism, social restrictiveness, or community mental health ideology. Gender adherence had a significant incremental effect on benevolence over and above the effects of sex. Therefore, hypothesis 4 was partially supported. 


\section{Discussion}

Understanding factors that affect attitudes toward persons with a mental illness can be key to addressing discrimination against them (Barney, Corser, Strosser, Hatch, LaFrance, 2017; Graham, Julian, \& Meadows, 2010; Henderson et al., 2016; Hunt \& Hunt, 2004; Leong \& Zachar, 1999; Masuda et al., 2009; Negri \& Briante, 2007; Pennington et al., 2016; Villani \& Kovess, 2017). Although past researchers have attempted to measure attitude differences in sex and gender, most researchers have used the terms interchangeably despite their conceptual differences. To further expand on these differences, the current study examined these constructs separately and measured differences in attitudes between these groups. Further, the current study measured the effect of sex and gender adherence, as well as their incremental effects, on differences in attitudes toward persons with a mental illness.

\section{Summary of Findings}

Hypothesis 1 stated that attitudes toward persons with a mental illness would differ between sexes. Specifically, participants who are male were hypothesized to hold more negative attitudes toward persons with a mental illness than would females. This hypothesis was not supported as the results of the study found no differences between sexes for all four dimensions of attitudes toward persons with a mental illness. These findings are consistent with previous studies that reported no significant attitude differences between sexes (Hampton \& Sharp, 2014; Hinkelman \& Granello, 2003; Wendt \& Shafer, 2016) but contradict previous studies that demonstrated sex differences (Chen \& Chandrasekara, 2016; Ewalds-Kvist et al., 2013; Kivari, 2009; Taylor \& Dear, 
1981; Upadhyay et al., 2016); it is important to note that gender and sex were not treated as different concepts in many of these studies. The lack of significant sex differences in attitudes in this study suggests that sex is not a useful predictor of attitudes.

Hypothesis 2 stated that that attitudes toward persons with a mental illness would differ between categories of gender adherence. Specifically, participants who adhere to a masculine gender were hypothesized to report more negative attitudes toward persons with a mental illness than would participants who adhere to a feminine gender. No hypotheses were made regarding those who adhere to neither gender (undifferentiated) or regarding those who adhere to both gender categories (androgynous). This hypothesis was only partially supported; the results indicated that participants who adhered to a feminine gender had more benevolent attitudes toward persons with a mental illness than did undifferentiated participants. No other gender categories had significant differences on the four attitude dimensions. These findings may be due to the convergence of feminine gender adherence items in the BSRI (e.g., "sympathetic" and "understanding") with the benevolent items on the CAMI scale (e.g., "We need to adopt a far more attitude toward the mentally ill in our society."). Adherence to a masculine or adherence to both masculine and feminine gender roles does not appear to be related to attitudes toward persons with a mental illness, but adherence to a feminine gender - when that gender is measured using benevolence-related terminology - produces attitude differences when compared to participants who adhere to neither masculine nor feminine gender roles.

Hypothesis 3 stated that sex would not explain attitudes toward persons with a mental illness above and beyond the effect of gender role adherence. The results from the set of 
hierarchical multiple regression analyses indicated that adherence to a feminine gender contributed to variance in benevolent attitudes. However, when controlling for gender role adherence, sex did not explain attitudes above and beyond the effect of gender adherence on all four attitude dimensions, thereby supporting the third hypothesis. Sex does not appear to explain variance in attitudes toward persons with mental illness beyond what measuring gender adherence can provide.

Hypothesis 4 stated that gender role adherence would explain attitudes toward persons with a mental illness above and beyond the effect of sex. This hypothesis was only partially supported. Results indicated that gender adherence did not explain attitudes above and beyond the effect of sex on the dimensions of authoritarianism, social restrictiveness, or community mental health ideology. However, gender adherence did explain benevolent attitudes above and beyond the effect of sex; no particular gender adherence category explained attitude differences. Gender adherence explains variance in benevolent attitudes toward persons with mental illness above and beyond sex.

\section{Theoretical Implications}

The current study presents a number of theoretical implications. First, it contributes to a slowly growing body of literature that demonstrates the inconsistency of sex as a significant predictor of attitudes toward persons with a mental illness. The results of the current study found no significant attitude differences between sexes. The results also found that sex did not significantly explain variance in authoritarianism, benevolence, social restrictiveness, or community mental health ideology, both on its own and incrementally over and above the effect of gender adherence. These findings contribute to 
literature that aims to understand sex differences in attitudes toward persons with a mental illness.

Second, the current study examined an additional method of measuring gender role adherence, and therefore contributed to closing a gap in understanding the relationship between gender and attitudes toward persons with a mental illness separately from the construct of sex. Differences in attitudes were found only between participants who adhered to a feminine gender and participants who adhered to neither gender on the benevolence dimension of attitudes. These results diverge from previous findings that adhering to a specific gender (i.e., masculine vs feminine) produces attitude differences (Hinkelman \& Granello, 2003; Kivari, 2009). The utilized measurement of gender adherence could explain this discrepancy. Whereas previous studies have measured gender using a person's attitude toward gender-specific experiences and behaviors (Hinkelman \& Granello, 2003; Kivari, 2009), the current study measured adherence to gender-specific characteristics and did so covertly. The current study did not account for the attitudinal and behavioral aspects of gender, nor did it make explicit the gendered nature of the traits of the BSRI. Therefore, gender characteristics may not be a useful dimension of gender to take into account when measuring the relationship between gender adherence and attitudes toward persons with a mental illness.

\section{Practical Implications}

A practical application of the current study involves diversity and inclusivity trainings. As referenced in Hunt and Hunt (2004), "negative attitudes toward people with disabilities appear to stem from faulty information in the belief system about disability 
and about people who have disabilities" (p. 269). Workshops and training offerings can provide a method by which discrimination is reduced through changes in attitudes (Barney et al., 2017; Negri \& Briante, 2007; Pennington et al., 2016). A focus on or appeal to the benevolent characteristics and benevolent attitudes of a given audience could prove beneficial to anti-discrimination training and workshops (Barke, Nyarko, \& Klecha, 2010). Additionally, due to the lack of significant findings regarding gender and sex, trainers could tailor workshops based on factors of the intended audience that have been more consistently related to attitudes toward persons with mental illness, such as age, race or ethnicity, educational attainment, and previous social relationships with persons with a mental illness.

\section{Strengths of the Study}

There was a sizable number of participants who fell into each of the four gender adherence categories. By having similar sizes of groups, the study's findings can be considered more rigorous than if the group sizes were unequal. The use of the BSRI also can be considered a strength of the study, as it measured gender adherence covertly through the use of traits that were not explicitly gender- or sex- specific. Thus, participants were not primed to respond in a socially desirable way based on how well they thought their personality should adhere to their culture's gender characteristics (Frable, 1989). Further, the multidimensional CAMI scale provides multiple lenses through which researchers can understand beliefs, cognitions, and feelings toward persons with a mental illness. Because this study utilized a multidimensional approach 
toward attitudes, it offered a nuanced insight into how attitudes differ on different dimensions of the construct.

\section{Limitations and Directions for Future Research}

The current study has a handful of limitations. First, as noted above, participants who endorsed feminine items on the BSRI might have also been more inclined to indicate positive benevolent attitudes due to the similarity between the two subscales. Thus, the relationship between feminine gender adherence and benevolent attitudes may be due to a conceptual overlap of the constructs, rather than due to a relationship between two different constructs. Future studies should take into account the potential for this type of overlap when choosing scales to measure gender adherence and attitudes toward individuals with mental illness constructs.

Another limitation is the exclusion of participants who were transsexual or intersex. The majority of participants fell into the binary of male or female; two participants identified themselves as falling outside the binary and were removed from the final analyses. Studies that include individuals outside of the male-female binary are few, which leads to a gap in understanding the attitudes of this population. Future studies should include a higher number of these individuals to help fill this gap that the current study was unable to address.

Finally, the scale utilized in the current study did not account for other dimensions of gender. One area that should be considered in future studies is the alignment of a measure to a person's identified gender or sex (e.g., did participants who self-identified as being a "female" gender or being assigned female at birth also demonstrate adherence to feminine 
traits on the BSRI). Past studies have demonstrated behavioral and gender-related attitude differences between cross-typed (e.g., masculine individuals who are female) and sextyped (e.g., masculine individuals who are male) individuals (Bem, 1981; Bem, Martyna, \& Watson, 1976; Frable, 1989; Schmitt \& Millard, 1988). Future studies would benefit from taking into account these categories in order to assess if these alignments are relevant to attitudes toward persons with a mental illness. Moreover, gender was defined in the current study by a culture's preferred alignment of a person's sex and their nonphysical characteristics, behaviors, and attitudes. As noted above, only a person's characteristics were measured in the current study. This leaves considerable uncertainty regarding whether measuring a different dimension of gender would have produced substantial attitude differences, especially given findings of gender differences in previous studies on these topics. Tapping into other aspects of a person's gender such as behavior or attitudes toward gender-specific topics could address the gap produced by the current study.

\section{Conclusion}

The present study examined the differences between sex and gender, and their individual relationship with attitudes toward persons with a mental illness. Specifically, this study's aim was to determine if attitudes would be more positive for females and for those who adhered to a feminine gender, and if attitudes would be more negative for males and for those who adhered to a masculine gender. Further, incremental effects of sex and gender were individually tested for these attitudes. The findings of this study demonstrated that only those who adhered to a feminine gender, relative to those who did 
not adhere to masculine and feminine genders, had significantly more benevolent attitudes. Additionally, this study showed that gender significantly explained differences in benevolent attitudes beyond the effects of sex.

Although sex and gender have long been cited as important predictors of attitudes toward various topics, they do not necessarily provide substantial insight as to whether a person of a particular sex or gender may have more positive or negative attitudes toward other persons with a mental illness. Future researchers studying the topic of attitude differences, however, should continue to take into account the multidimensionality of attitudes toward individuals with a mental illness. 


\section{References}

Alexander, L. A., \& Link, B. G. (2003). The impact of contact on stigmatizing attitudes toward people with mental illness. Journal of Mental Health, 12, 271-289.

Arora, P. G., Metz, K., \& Carlson, C. I. (2016). Attitudes toward professional psychological help seeking in south Asian students: Role of stigma and gender. Journal of Multicultural Counseling and Development, 44, 263-284. doi:10.1002/jmcd.12053

Artis, J. E. (1997). Gendered perceptions of dependency in discussions of mental illness. Journal of Health and Social Behavior, 38, 387-402.

Ballard-Reisch,, D., \& Elton, M. (1992). Gender orientation and the Bem Sex Role Inventory: A psychological construct revisited. Sex Roles, 27 291-306. doi.org/10.1007/BF00289930

Barke, A., Nyarko, S., \& Klecha, D. (2010). The stigma of mental illness in Southern Ghana: attitudes of the urban population and patients' views. Social Psychiatry and Psychiatric Epidemiology, 46, 1191-1202.

Barney, S. T., Corser, G. T., Strosser, G. L., Hatch, D. L., \& LaFrance, K. (2017). Servicelearning in abnormal psychology: Softening the implicit stigma against the mentally ill. Scholarship of Teaching and Learning in Psychology, 3, 151-162. doi.org/10.1037/st10000083

Bem, S. L. (1974). The measurement of psychological androgyny. Journal of Consulting and Clinical Psychology, 42, 155-162.

Bem, S. L. (1975). Sex role adaptability: One consequence of psychological androgyny. Journal of Personality and Social Psychology, 31, 634-643.

Bem, S. L. (1981). The BSRI and gender schema theory: A reply to Spence and Helmreich. Psychological Review, 88, 369-371.

Bem, S. L., Martyna, W., \& Watson, C. (1976). Sex typing and androgyny: Further explorations of the expressive domain. Journal of Personality and Social Psychology, 34, 1016-1023.

Brockington, I., Hall, P., Levings, J., \& Murphy, C. (1993). The community's tolerance of the mentally ill. The British Journal of Psychiatry, 162, 93-99.

Chen, Z., \& Chandrasekara, W. S. (2016). The psychological mechanism of stigmatizing attitudes toward help seeking behavior for mental health problems. International Journal of Management, Accounting and Economics, 3, 720-734. 
Cremonini, V., Pagnucci, N., Giacometti, F., \& Rubbi, I. (2018). Health care professionals attitudes toward mental illness: Observational study performed at a public health facility in northern Italy. Archives of Psychiatric Nursing, 32, 24-30.

doi.org/10.1016/j.apnu.2017.09.007

Ewalds-Kvist, B., Högberg, T., \& Lützén, K. (2013). Impact of gender and age on attitudes towards mental illness in Sweden. Nordic Journal of Psychiatry, 67. doi:10.3109/08039488.2012.748827

Frable, D. E. S. (1989). Sex typing and gender ideology: Two facets of the individual's psychology that go together. Journal of Personality and Social Psychology, 56, 95-108.

Gewurtz, R. E., Langan, S., \& Shand, D. (2016). Hiring people with disabilities: A scoping review. Work, 54, 135-148. doi:10.3233/WOR-162265

Goodman-Delahunty, J. (2000). Psychological impairment under the Americans with Disabilities Act: Legal guidelines. Professional Psychology: Research and Practice, 31, 197-205.

Gordon, C. T. (2003). Types of mental illness. Retrieved from https://namica.org/resources/mental-illness/types-mental-illness/

Graham, A. L., Julian, J., \& Meadows, G. (2010). Improving responses to depression and related disorders: evaluation of a innovative, general, mental health care workers training program. International Journal of Mental Health Systems, 25, 1-13. doi.org/10.1186/1752-4458-4-25

Hamburger, M. E., Hogben, M., McGowan, S., \& Dawson, L. J. (1996). Assessing hypergender ideologies: Development and initial validation of a gender-neutral measure of adherence to extreme gender-role beliefs. Journal of Research in Personality, 30, 157-178. doi.org/10.1006/jrpe.1996.0011

Hampton, N. Z., \& Sharp, S. (2014). Internal motivation to respond without prejudice as a mediator of gender-attitudes toward mental illness. Journal of Rehabilitation, 80, 30-39.

Hebl, M. R., \& Skorinko, J. L. (2005). Acknowledging one's physical disability in the interview: Does "when" make a difference? Journal of Applied Social Psychology, 35, 2477-2492.

Henderson, C., Robinson, E., Evans-Lacko, S., Corker, E., Rebollo-Mesa, I., Rose, D., \& Thornicroft, G. (2016). Public knowledge, attitudes, social distance and reported contact regarding people with mental illness 2009-2015. Acta Psychiatrica Scandinavia, 134, 22-33. doi.org/10.1111/acps.12607

Hinkelman, L., \& Granello, D. H. (2003). Biological sex, adherence to traditional gender roles, and attitudes toward persons with mental illness: An exploratory investigation. Journal of Mental Health Counseling, 25, 259-270. 
Högberg, T., Magnusson, A., Ewertzon, M., \& Lützén, K. (2008). Attitudes towards mental illness in Sweden: Adaptation and development of the Community Attitudes towards Mental Illness questionnaire. International Journal of Mental Health Nursing, 17, 302-310. doi:10.1111/j.1447-0349.2008.00552.x

Hunt, C., \& Hunt, B. (2004) Changing attitudes toward people with disabilities: Experimenting with an educational intervention. Journal of Managerial Issues, 16, 266-280.

Hunter, K. N., Rice, S., MacDonald, J., \& Madrid, J. (2014). What are the best predictors of opinions of mental illness in the Indian population? International Journal of Mental Health, 43, 35-51. doi:10.2753/IMH0020-7411430203

Introduction to the ADA. (n.d.). In information and technical assistance on the Americans with Disabilities Act. Retrieved from ada.gov/ada_intro.htm

Jans, L. H., Kaye, H. S., \& Jones, E. C. (2011). Getting hired: Successfully employed people with disabilities offer advice on disclosure interviewing, and job search. Journal of Occupational Rehabilitation, 22, 155-165. doi:10.1007/s10926-011-9336-y

Kivari, C. (2009). Beliefs about mental illness: The influence of gender-roles on what we take from television. doi.org/10.14288/1.0086049

Kukla, M., Bond, G. R., \& Xie, H. (2012). A prospective investigation of work and nonvocational outcomes in adults with severe mental illness. The Journal of Nervous and Mental Disease, 200, 214-222. doi:10.1097/NMD.0b013e318247cb29

Leong, F. T., \& Zachar, P. (1999). Gender and opinions about mental illness as predictor of attitudes toward seeking professional psychological help. British Journal of Guidance and Counseling, 27, 123-132.

Madianos, M.G., Zartaloudi, A., Alevizopoulos, G., \& Katostaras, T. (2011). Attitudes toward help-seeking and duration of untreated mental disorders in a sectorized Athens area of Greece. Community Mental Health Journal, 47, 583. doi.org/10.1007/s10597-011-9404-y

Marini, M. M. (1990). Sex and gender: What do we know? Sociological Forum, 5, 95-115. 
Masuda, A., Hayes, S. C., Twohig, M. P., Lillis, J., Fletcher, L. B., \& Gloster, A. T. (2009). Comparing Japanese international college students' and U.S. college students' mental-healthrelated stigmatizing attitudes. Journal of Multicultural Counseling and Development, 37, 178-189.

Mental disorders. (2014). Retrieved from https://medlineplus.gov/mentaldisorders.html

Morris, R., Scott, P. A., Cocoman, A., Chambers, M., Guise, V., Välimäki, M., \& Clinton, G. (2012). Is the Community Attitudes towards the Mentally Ill scale valid for use in the investigation of European nurses' attitudes towards the mentally ill? A confirmatory factor analytic approach. Journal of Advanced Nursing, 68, 460-470. doi:10.1111/j.13652648.2011.05739.x

Millar, R. (2017). Australian undergraduate nursing students' opinions on mental illness. Australian Journal of Advanced Nursing, 32, 34-42.

Negri, L., \& Briante, G. (2007). My colleague is a mentally ill disabled person. Can contact at work change attitudes towards mental illness? The International Journal of Diversity in Organizations, Communities, and Nations, 7, 267-276.

Nunnally, J. C. (1978). Psychometric Theory (2nd ed.). New York: McGraw-Hill.

Pennington, C. R., Campbell, C., Monk, R. L., \& Heim, D. (2016). The malleability of stigmatizing attitudes: Combining imagined social contact with implicit attitude feedback. American Journal of Psychiatric Rehabilitation, 19, 175-195. doi.org/10.1080/15487768.2016.1171175

Pentony, C. G. (1980). Gender, sex typing, and gender identity. American Psychologist, 35, 941942. doi.org/10.1037/0003-066X.35.10.941

Phelan, J. E., \& Basow, S. A. (2007). College students' attitudes toward mental illness: An examination of the stigma process. Journal of Applied Social Psychology, 37, 2877-2902.

Reta, Y., Tesfaye, M., Girma, E., Dehning, S., \& Adorjan, K. (2016). Public stigma against people with mental illness in Jimma Town, Southwest Ethiopia. PLOS ONE, 11, 1-14. doi:10.1371/journal.pone.0163103

Roberts, L. L., \& Macan, T. H. (2006). Disability disclosure effects on employment interview ratings of applicants with nonvisible disabilities. Rehabilitation Psychology, 51, 239-246. doi:10.1037/0090-5550.51.3.239

Russinova, Z., Griffin, S., Bloch, P., Wewiorski, N. J., \& Rosoklija, I. (2011). Workplace prejudice and discrimination toward individuals with mental illnesses. Journal of Vocational Rehabilitation, 35, 227-241. doi:10.3233/JVR-2011-0574 
Schmitt, B. H., \& Millard, R. T. (1988). Construct validity of the Bem Sex Role Inventory (BSRI): Does the BSRI distinguish between gender-schematic and gender-aschematic individuals? Sex Roles, 19, 581-588.

Smith, A. L., \& Cashwell, C. S. (2011). Social distance and mental illness: Attitudes among mental health and non-mental health professionals and trainees. The Professional Counselor: Research and Practice, 1, 13-20.

Strohmer, D. C., Grand, S. A., \& Purcell, M. J. (1984). Attitudes toward persons with a disability: An examination of demographic factors, social context, and specific disability. Rehabilitation Psychology, 29, 131-145.

Taylor, S. M., \& Dear, M. J. (1981). Scaling community attitudes toward the mentally ill. Schizophrenia Bulletin, 7, 225-240.

Upadhyay, R., Srivastava, P., Singh, N. K., \& Poddar, S. (2016). Community attitudes and stigma toward mental illness: A gender perspective. Journal of Psychosocial Research, 11, 335-341.

Venkatesh, B. T., Andrews, T., Mayya, S. S., Singh, M. M., \& Parsekar, S. S. (2015). Perception of stigma toward mental illness in South India. Journal of Family Medicine and Primary Care, 4, 443-453. doi:10.4103/2249-4863.161352

Villani, M., \& Kovess, V. (2017). Could a short training intervention modify opinions about mental illness? A case study on French health professionals. BMC Psychiatry, 133, 1-9. doi:10.1186/s12888-017-1296-0

von Schrader, S., Malzer, V., \& Bruyère, S. (2014). Perspectives on disability disclosure: the importance of employer practices and workplace climate. Employee Responsibilities and Rights Journal, 26, 237-255. doi:10.1007/s10672-013-9227-9

Wendt, D., \& Shafer, K. (2016). Gender and attitudes about mental health help seeking: Results from national data. Health and Social Work, 41, 20-28. doi:10.1093/hsw/hlv089

West, C., \& Zimmerman, D. H. (1987). Doing gender. Gender \& Society, 1, 125-151. doi.org/10.1177/0891243287001002002

Williams, S. L., Cabrera-Nguyen, E. P., \& Johnson, S. D. (2018). Examining the impact of race/ethnicity and gender intersectionality on preferences of social distance from individuals with mental health conditions. Journal of Human Behavior in the Social Environment, 28, 370-380. doi:10.1080/10911359.2018.1433572 
Wolff, G., Pathare, S., Craig, T., \& Leff, J. (1996). Community attitudes to mental illness. The British Journal of Psychiatry, 168, 183-190.

Yuan, Q., Abdin, E., Picco, L., Vaingankar, J. A., Shahwan, S., Jeyagurunathan, A., \& Sagayadevan, V. (2016). Attitudes to mental illness and its demographic correlates among general population in Singapore. PLOS ONE, 11. doi.org/10.1371/journal.pone.0167297 